\title{
A Regenerative Design Study on Design Elements of Traditional Cantonese Residence in Countryside Bed and Breakfast Tourism
}

\author{
Lu Ying, Zhou Zewen \\ Guangzhou College of Technology and Business, Guangzhou, Guangdong, 510850, China
}

Keywords: Rural Culture; Countryside Bed and Breakfast; Traditional Cantonese Residential Architecture; Creative Design

\begin{abstract}
In the new media era of the 21st century, the world is developing as a community that "seeks a common ground while reserving differences", wherein, "differences" stand out due to the national value. In this context, as far as design is concerned, "countryside bed and breakfast" as part of new countryside construction and development is focused on metaphors indicating sense of history and connotation of human life, built with characteristics, oriented in healthy, green and sustainable development, and established in the key philosophy--"design is for the sake of a better life", which highlights the inheritance of "contextualism" and embarks on a creative period when modern design philosophy regenerates the traditional culture. And the philosophy of traditional Cantonese residential architecture design is not only an embodiment of this type of culture but also an activity. Since architecture presents human lifestyle and attitude and distinctive characteristics of regional culture, a combination and transformation of design elements of traditional residence and new materials, processes and techniques gives a reference for design practice of Lingnan countryside bed and breakfast.
\end{abstract}

\section{Introduction}

\subsection{Inheritance and reservation of rural culture}

In the wake of economic development and change in the nature of farmland, "countryside", "farmers" and "memories about countryside" have gradually become words of mouth and it is hard to inherit the "rural culture" by a "memory-based" description. Fortunately, "new countryside" construction offers new development models for sustaining the "rural culture", among which, "bed and breakfast" as one of contributors to new countryside construction optimizes the economic structure of the new countryside on the ground of inheriting characteristics of local culture and maintaining former farming environment, folk culture, food culture and interpersonal communication model of villagers. Certainly, such a "bed and breakfast design" aimed at inheritance of "rural culture" is different from the commercial bed and breakfast development model based on tourism development in essence.

\subsection{Boost of regional economic development}

Economic construction in the new socialist countryside is mainly concerned with building a long-term mechanism to increase revenue of farmers, make them well off and narrow the urban-rural gap based on development of rural production in all respects. For instance, Timian Town, Huadu District, Guangzhou City, is one of the eight mountainous towns in Guangzhou and has a beautiful scenery, primitive folk culture and featured food. And west of Timian Town, there is a Hongshan Village--the first "national civilization village" in Huadu District, where villagers sustain the farming lifestyle of growing such economic crops as rice, vegetable and peanut. Its "countryside bed and breakfast" is built with distinctive characteristics of rural culture of Lingnan, which provides an accommodation different from a hotel or guesthouse and has a highlight that villagers lead tourists to experience the fun of farming to enhance quality of personal life and increase local economic revenue. 


\subsection{Healthy, green and sustainable development}

"New countryside construction" is a process to accept, digest, absorb and practice modern civilization step by step. It is given a clarity in development of "countryside bed and breakfast"--how to change ideas of villagers, improve quality of villagers, enhance service quality of tourism, and establish the sustainable development philosophy of inheriting local culture and protecting the ecological environment among others. Herein, the design philosophy of "traditional Cantonese residence" embodies the "local culture", shows human lifestyle and attitude and has distinctive characteristics of regional culture. Hence, a study on "countryside bed and breakfast" in Lingnan aimed at cultural inheritance is needed to sort out and apply sites of architectural environment, architectural construction techniques, and construction materials by inherited and creative design philosophy and maintain the "local context", "folk culture" and "sustainable development of natural environment" by architectural language to protect and improve residents' own residential environment.

\section{Design Language of Countryside Bed and Breakfast}

\subsection{Climate design}

The very first production activity of human is environmental design and cave building, nest building and high-rise building in the civilization period show the feature of accommodating different climatic circumstances. Specifically speaking, Cantonese bed and breakfast is designed in accordance with Cantonese geographic and climatic characteristics--hot and rainy and oriented in ventilation, day lighting and rain resistance. Through an analysis on site, ventilation, day lighting and scope of shadow of architecture, it adopts such architectural elements as sun-, rain- and fire-proof walls and eaves. For instance, in order to shelter the floor from solar radiation, inter-wall pleioblastus pygmaea, flower stands and shelves add a natural thermal insulation barrier for architecture to spare indoor walls and floor from direct solar radiation and yield pretty good cooling effects. In addition, courtyards, open alleyways and door and window lattices are used to reinforce ventilation effects and meet residents' needs in life.

\subsection{High local accommodation}

Bed and breakfast is part of countryside, hence the Cantonese residential architecture design follows the principle of using local materials, more to the point, local water- and heat-proof red sandstone as floor decoration or architectural decoration materials to decorate by bright colors and manifest the eco-friendly and green design philosophy. Besides, plants in Cantonese residential architecture design is characterized by literature appreciation for the allocation of plants often combines with poetry in literature to form abstract symbolic language to facilitate studies on "architecture".

\section{Creative Design of Elements in Traditional Cantonese Residential Architecture Design}

Regional architectural elements comprising decoration, internal structure, and spatial pattern as part of representation of architecture-related information makes a thorough inquiry into the philosophy of life. To be specific, tangible resources of traditional Cantonese residential architecture success the intangible rural context.

\subsection{Copy}

At first, human used clear signs and symbols to express understanding about space. And copy is the best way to hold firm to the essence of national architecture and present the restoration of a plane layout, facade structure and ceiling ridge system. It is a direct and comprehensible design technique, whose difficulty lies in how to get familiar with traditional building techniques and restore building materials. It is of high reference value to restore the traditional residential architectural environment for countryside bed and breakfast. 


\subsection{Partial application}

The utilization of roof, column and tie construction, door and window lattices, and tympanum among other typical residential architectural elements in modern architecture design is regarded as a technique to inherit and develop the traditional culture. In addition to inheriting traditional residential architectural elements and patterns, this technique develops non-mechanical application in design and highlights a natural fusion with modern architecture mostly based on the style orientation and cultural embodiment of traditional design elements. In countryside bed and breakfast architecture reconstruction in particular, such components of traditional architecture as doors and windows are locally restored to present delights of the former life in rural culture and reduce reconstruction cost.

\subsection{Extraction and collage}

Extraction and collage is a more flexible technique than simply copying, which subtracts and collages traditional architectural elements in a well-designed way. As a result, such elements will have simple forms and a variety of functions. This technique is a flexible design on traditional architectural elements generally including colors, materials and ornaments in traditional residential architecture. Architectural colors: pinky white of walls, greenish black of tiles, and a variety of colors of Manchuria windows; architectural materials: wood, tile, stone and ceramic; components of architectural model: tympanum on the wall surface, ice crack in the window and see-through sculpture on the ridge, to name a few.

\subsection{Reconstruction and deconstruction}

Traditional residential architectural elements and symbols can be reprocessed in form to present a pattern more easily matching the modern architecture. On that account, the reconstruction technique can be used to break or disintegrate the former construction system of the traditional architecture before modern design construction methods are employed subject to practical needs and subjective creation ideas to establish a new order in the system. The so-called deconstruction favors that elements and symbols are disintegrated, broken, incomplete and centerless and uses new materials and process in modern design to reinvigorate the indoor form. Shenzhen Vanke The Fifth Village is a typical design case of this technique.

\subsection{Inheritance of design philosophy in form}

Cantonese open cultural characteristics are shown as integration of humanistic feelings in architecture. Cantonese residential architecture is combined with ecological environment, where local materials are used and local conditions are taken advantage of. Cantonese residential architecture has such good functional characteristics as thermal insulation, sunshade and ventilation and a free layout. In countryside bed and breakfast in particular, human activity space is moved outward and all types of open space such as terraces, open corridors and halls are fully arranged to return to the traditional "courtyard" environment and atmosphere to enable humans to back to nature from closed indoor environment given a mild climate. In the design of countryside bed and breakfast, combination of climatic conditions and humanistic elements is a focus of the architecture design inheritance philosophy.

\section{Conclusion}

The design language of traditional Cantonese residential architecture keeps combining all kinds of social elements such as economy, culture and politics with its own inherent characteristics in evolution, which shows a certain value in social culture, economy, aesthetics and application as time goes by. The contextual characteristics of the residential architecture are applicable to rural culture building in poverty relief and development work. More to the point, good ecological environment is effectively taken advantage of and poverty relief and development is combined with rural folk building to set the tone for bed and breakfast construction in the new countryside. 


\section{References}

[1] Liu Xianjue, Theories of Modern Architecture-Chinese Architecture [M], Beijing: China Architecture \& Building Press. August 2011. P346

[2] Ma Li. Application of Architectural Symbols in Design [J]. South Architecture, 2006(7): 9—11

[3] Feng Zhuoru. A Discussion on Artistic Characteristics of Lingnan Architecture and Anhui-style Architecture [J]. Art and Literature for the Masses, 2010, (16): 209-210

[4] Hu Huiqin. Traditional Residence and Sustainable Development [J]. Residential Architecture and Culture, 2004, (6).

[5] Gao Fan. The Application of Traditional Building Material in the Design of Bed and Breakfast--Taking Beijing Beigou Village B\&B Design as an Example, A Master Dissertation of Shanxi University [D], 2017, (6). 